\title{
The number of virtual learning environment and their effective using impact on students' information literacy
}

\author{
Pan Xiaoyun ${ }^{1 *}$, Mao Siqi ${ }^{2}$ \\ ${ }^{1,2}$ College of Liberal Arts, Wenzhou-Kean University, Zhejiang, China
}

\section{Keywords \\ Virtual learning environment Information literacy \\ Higher education \\ Chinese traditional university}

Received: 16 January 2018 Accepted: 26 February 2018 Published: 18 April 2018

\begin{abstract}
This research studied the relationship between Virtual Learning Environment (VLE) and university students' information literacy from two aspects: the number of VLE platforms' influence on students' information literacy; the quality and quantity of sources students tend to search and use VLE required course. University students' different information literacy levels result in varying degrees of acceptance in VLE required environments; the various VLE involved environments have some interrelationship with students. The researchers predicted that if the number of VLE platforms students could access is higher then higher information literacy level university students would reach. Students' information literacy levels could be evaluated by the quality and quantity of their sources. However, the relationships between the number of VLE platforms, students' information literacy, and the source quality and quantity are not simply pairwise correlations. The research was located in Zhejiang, China; 160 students from five universities were randomly selected to participate in the study. Both questionnaires and interviews were conducted in the case study to collect relevant data. The data analysis exhibited that the number of VLE platforms accessible for students on campus has a weak positive correlation; however, students' familiarity with a certain number of different VLE platforms is relatively more influential on students' information literacy level.
\end{abstract}

(C) 2018 The Author(s). Published by TAF Publishing.

\section{INTRODUCTION}

VLE platforms are becoming an integrated part of Chinese high education system, but the degree of compatibility in different universities varies. The varying number of VLE platforms, the quality of VLE platforms and the source provided by VLE platforms on campus can affect university students' information literacy level.

\section{The Statement of Problem}

Students in Chinese universities are required to write academic papers, process data, and research on curriculum related topics, which demand high information literacy. The Chinese university students who have low information literacy are likely to have poor academic writing performance because "[they] cannot locate, evaluate and effectively use the needed information" (Siti Fatimah, Norhafizah, Noryanti, Rozieana, \& Hassan, 2015; Webber \& Johnston, 2000). However, if students have more virtual learning platforms to access to on campus, they may have higher infor- mation literacy.

\section{Definition of Terms \\ VLE}

VLE, which is also known as Course Management System (CMS) or Learning Management System, is a system that can provide training information, assessment or other communication tools for people to achieve practicing or learning goals online (Hashim, Salam, \& Mahfuzah Mohamad, 2017; Koroieva, 2017; Oxford University Press, 2016). In high education institutions, it offers students the opportunity to access different learning tools or learning resources without time or place limitation. As a set of web-based learning platforms, VLE is designed to make all the components of a class, such as course information, course content, teacher assistance, discussion boards, document sharing systems, and academic material to be more available to students (Martins \& Kellermanns, 2004; Silva \& Madushani, 2017; Suharti \& Pramono, 2016; Supratman, 2015).

\footnotetext{
*corresponding author: Pan Xiaoyun

†email: Panxiaoyun064@wku.edu.cn
} 
VLE platforms adopted in universities require students to have more self-efficacy on time management and independent learning. VLE has the possibility to improve communication efficiency and effectiveness between students and teachers; furthermore, to assess as enhancement for faceto-face teaching methods. Students acceptance affects significantly the extent of succeeding with VLE platforms assistance (Boonyarattanasoontorn, 2017; Martins \& Kellermanns, 2004; Pengmanee, 2016; Rabahi, Yusof, \& Awang, 2016). For example, Blackboard and Moodle.

\section{Information Literacy}

Information literacy refers to "recognize when information is needed and have the ability to locate, evaluate, and use effectively the needed information" (Webber \& Johnston, 2000). More specifically in the academic field, it includes "how to use resources such as online databases, OPAC, journal articles, as well as experts and authoritative bodies to obtain knowledge and achieve academic tasks" (Klomsri \& Tedre, 2016).

\section{Background of the Study}

Wenzhou-Kean University is a Sino-western university founded in 2012. The relationship is established between the Wenzhou local government and Kean University in New Jersey, which offers the university an international environment and American education system. Now it has 1918 students on campus, and 580 are sophomores.

The University of Nottingham Ningbo is also a Sino-western university, and it is a private university. It was founded in 2004, and now there are around 1750 sophomores on campus. The teaching system completely follows the curriculum of the University of Nottingham in England, which is similar to British style.

Wenzhou Medical University (WMU) is a traditional Chinese university, and it is a medical specialized university with integrated courses and master degree program. WMU was founded in 1958, and now there are 2133 sophomores on campus.

Ningbo University is a university with comprehensive disciplinary majors which was founded in 1986. Now it has 5025 sophomores on campus.

Zhejiang University City College is a traditional Chinese university. Zhejiang University and the Hangzhou government have been running this university jointly since 1999 . Chinese Ministry of Education regards it as an independent college which can provide qualified high education. Now it has 2361 sophomores on campus.

All of these universities have different characteristics, and one common thing can be found, according to some early communication researchers did between universities, among all five universities is that students can access VLE platforms on campus. VLE platforms have been an important part of their education system, but the degree of compatibility and students' acceptance varies from one to another.

\section{Significance of the Study}

The findings of this research study will be beneficial to the freshmen and sophomores from the five institutions studied. The study analyses the relationship between the number of VLE platforms used by Chinese university students on campus and their information literacy level, and offers the possible solutions to help students improve their information literacy. In the field of research, this study help fills the blank of Chinese students' information literacy and VLE platforms.

\section{REVIEW OF RELEVANT LITERATURE}

Many students' information literacy level is not adequate for high education source selecting and document learning (Britt \& Aglinskas, 2002; Ngwaru, 2017). However, the information literacy capacity applied totechnology are becoming sourcing can be improved by simple intervention, like a tutorial that provides direct instruction on sourcing for author related information can bring significant change upon college students sourcing ability (Britt \& Aglinskas, 2002).

As media and technology are becoming an integral part of education system, the ever-increasing proportion of misinformation phenomenon suggests that university students should possess critical analysis and higher information literacy. Students' information can be built up through "practicing finding the most applicable information, assessing media for validity, and documenting their own work appropriately" (Judy, 2016). The relevant degrees of source to students' initial topic and the source validly should be considered as essential elements (Judy, 2016).

\section{Hypothesis}

If sophomores in Chinese universities can access more VLE platforms, then they tend to have higher information literacy level.

\section{THEORETICAL FRAMEWORK}

\section{Choice Theory}

According to Irvine (2015) Glasser's choice theory considers that each person desires to meet the five basic psychological needs: "Survival, freedom, power, belonging, and 
fun". The "psychological survive" (Irvine, 2015) in the survival need refers to safety and comfortableness. If students can access many VLE platforms, they would have the feeling of owning a big database, which provides the students psychological comfort. Therefore, they are willing to use the VLE platforms to search needed information and improve their information literacy unconsciously.

Glasser also argues that the most important concepts shall be applied in the real situation that is "the quality world" (Zeeman, 2006). Students with different information literacy levels have different biological purposes; they tend to choose the resources that satisfied their psychological needs well reflected in VLE as well as the resources which are understandable in their information literacy level; this variation could be observed both in quality and quantity. Decision theory also has an essential position in the framework.

\section{Decision Theory}

Decision theory refers to "theory about decisions" (Hansson, 2005). Hansson illustrates that when a decisionmaker makes decisions, actually he "chooses between different alternatives" (Hansson, 2005). In addition, expected utility theory considers the results of the actions are usually predictable, so people may choose "an action that maximizes the expected value of the resulting utility" (Parmigiani \& Inoue, 2009). Compared to search information from other unfamiliar platforms, students are more likely to get useful information from the platforms they frequently use.

Hansson also suggests that people tend to "obtain as good as an outcome as possible" (Hansson, 2005); university students choose sources according to the standard they assume by their information literacy. Decision-making based on a choice of value-standard in life is the subject of moral philosophy (Hansson, 2005), it is an empirical process, which is closely related to students' different information literacy. The evaluation students made on VLE reflects their different levels of information literacy. Motivation theory is considered next.

\section{Motivation Theory}

Motivation theory is the theory of "why people think and behave as they do" (Weiler, 2005). According to Abraham Maslow's "hierarchy of needs", "self-actualization" is one of the basic needs (Weiler, 2005). After achieving the basic need, it will become a "motivator" (Weiler, 2005). Students are required to collect needed information, and they hope to satisfy the need of self-actualization. Accessing to more VLE platforms may help them meet the requirement more easily, which can contribute to the improvement of students' information literacy.

McClelland's acquired needs theory suggests that an individual's specific needs are acquired over time according to one's life experiences. In virtual studying environment, achieving higher academic performance by using VLE effectively offers students a chance to be motivated to accomplish the academic needs. Different resources will be determined by students' different information literacy they gathered previously. Higher-information-literacy students tend to have more specific and advanced academic needs, which require better resources or other external support (McClelland, 1961).

\section{METHODOLOGY Type of Research}

Case study is chosen as the primary method in this study, which is defined as "an empirical inquiry that investigates a contemporary phenomenon within its real-life context, especially when the boundaries between the phenomenon and context are not clearly evident" (Yin, 1984); through which researchers shall be able to make conclusion out of data collected from some typical units of an entirety. The real population of this study is beyond wholly covered due to practical reasons, so the case study is conducted to reach an agreed-on conclusion on the research problems raised in the research.

The study is addressed in Zhejiang province, and five universities: Wenzhou-Kean University (WKU), WMU, Ningbo University (NU), University of Nottingham Ningbo China (UNNC), and Zhejiang University City College (ZUCC) are selected as student source. These five universities vary differently in school history, population, and type which covers Sino-western university and traditional Chinese university. However, the education level of Zhejiang province might not be typical enough to represent all the Chinese universities, for the university students in less-developed regions do not have the same access possibility to VLE and less academic competency.

\section{Respondents}

From the five universities selected for this study, 160 students participated in the research survey. The students who participated in this study all had reached the lowest GPA 3.0. Age distribution shows the participants are majority 19-20 years old. This design was used to control individual differences in cognitive ability.

Wenzhou-Kean University: 19 male and 35 female sopho- 
mores; WMU: 8 male and 22 female sophomores; Ningbo University: 19 male and 13 female sophomores; University of Nottingham Ningbo China: 10 male and 13 female sophomores: Zhejiang University City College: 5 male and 16 female sophomores.

Researchers asked students in Wenzhou-Kean University privately to participant in the study, so the return rate is nearly $100 \%$. In other universities, the research survey was randomly given to student chatting groups with averagely 75 students each, which resulted in a lower return rate, about $40 \%$.

\section{Tools}

\section{Questionnaire}

A questionnaire includes basic information, VLE using situation and a rating scale "Information Competency Assessment Instrument" is sent to the participants to evaluate their' information literacy level. "Information Competency Assessment Instrument" https://goo.gl/ZS9eoc was explicitly designed to evaluate students' information literacy level; it contains 40 statements.

\section{Interview}

Interviews are conducted to collect sophomores' VLE using situation and detailed information of literacy information; also, the answers are used to verify the data authenticity for further data selecting.

\section{Scope and limitations}

The boundary of this study is VLE in education sphere; specifically, undergraduate-university-level education in China. This scope includes both Sino-western University and traditional Chinese university, and has a particular observation setpoint of Chinese sophomores' information literacy. Considering students need time to adjust to VLE required course, the population is set upon sophomores in China. Hence, the scope of this research covers VLE, VLE's application in education, and both Sino-western university and traditional university.

The raw data collected from field survey have some conflicts between the information provided by personal interviews. Due to the fact that personal interviews were conducted among students having higher willingness and credibility toward this research, researchers filtered and selected the data before analysis. The number of data covered is less than the designed sample size; this brought a guarantee of data accuracy, though reduced the representativeness of the data, the amount still reached the anticipated number.

\section{PRESENTATION AND ANALYSIS OF DATA}

As mentioned in 'Scope and Limitation' section, in order to ensure the accuracy of data in this study, the data used in the analysis havw been selected according to the interviews. The number of VLE platforms adopted on campus is an essential variable in the research; hence, for each university, researchers left out all the data which indicate the students in a specific university who can access equal or greater than 1.5 times of the interview results. The data covered in this section are collected from 151 participants.

According to the instruction provided by the rating-scale researchers used in the study, students' information literacy score was calculated and classified into three levels: low (<153), medium (204-154), and high (> 154). 99 (66\%) sophomores in this study are ranked in medium information literacy level, 44 (29\%) sophomores are ranked in low level, and only 8 (5\%) students reach the high information literacy level (Figure 1). Statistics for each number of VLE platforms respondents can access to suggest that, the majority (76\%) sophomores can use 36 different VLE platforms on campus; the population of sophomores who can access less than 3 or more than 6 VLE platforms is respectively $16 \%$ and $15 \%$. The statistics illustrate that, generally speaking, sophomore students in universities studied have multiple access to VLE platforms on campus, and extremely limited or abundant accessing to VLE platforms is minority situation.
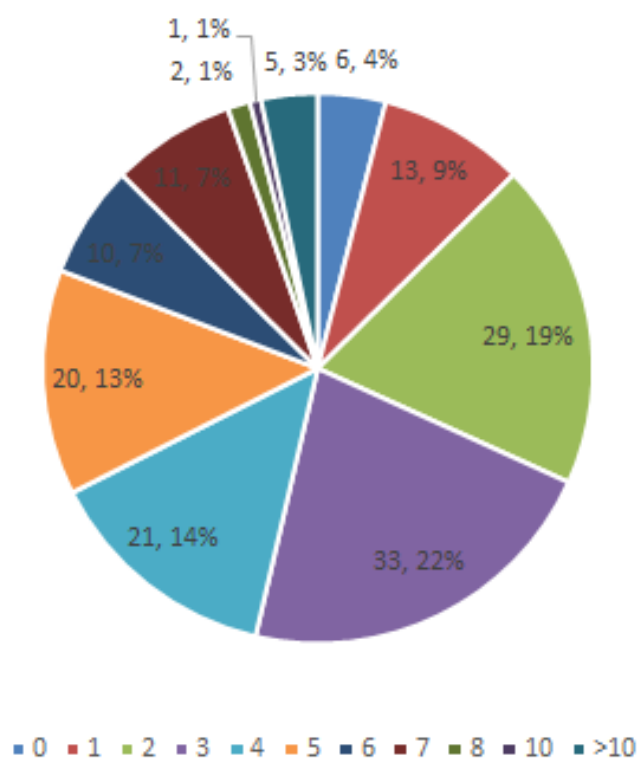

FIGURE 1. Number of VLE platforms respondents access on campus 
Both students who rank in low or medium information literacy level have a similar distribution in different numbers of VLE platforms on campus (Figure 2). However, the peak population for low information literacy level students appears when VLE platforms number is 2 . Among medium information literacy level students, the number is 3 , and the overall population of medium level sophomores who can access 4 to 6 VLE platforms is larger than low-level sophomores who can access 2 VLE platforms.

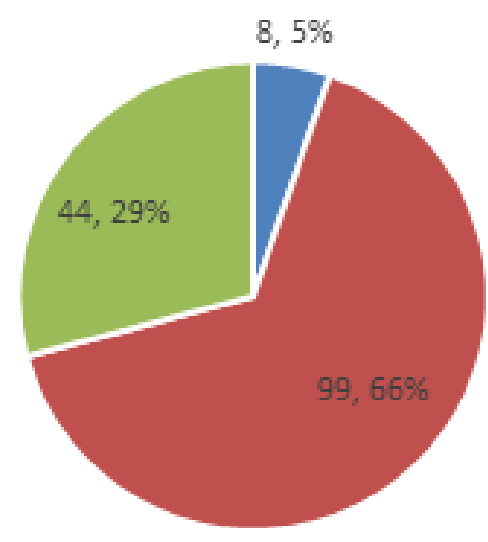

" High " Medium n Low

FIGURE 2. Information literacy level of respondents

Eight high information literacy level sophomores appear differently in the number of VLE platforms on campus. They can access 1, 2, 4, or 6 VLE platforms on campus, which means only low or medium students possibly can access extremely abundant VLE platforms according to this research. Researchers can only indicate that among the low or medium level of information literacy level Chinese students, the number of VLE platforms they can access might affect their information literacy level to some extent, but the clear relationships between both variables cannot be concluded (Figure 3).

The distribution in the two Sino-western universities is less similar to the general situation, and has more observable characteristic in the statistics. The sophomores from the University of Nottingham Ningbo China only rank in low and medium information literacy levels; though, the majority of both different levels population can access 4 or more than 4 VLE platforms on campus (Figure 4).

In Wenzhou-Kean University (Figure 5), majority students rank in medium information level, and the majority of them can access 3 or 4 VLE platforms in university. The population distribution in WKU and the University of Nottingham Ningbo China is distinguished, for the statistics are centralized; it illustrates that in Sino-western university, individual information literacy level might be affected by the VLE required environment, and tends to be close to the average information literacy level.

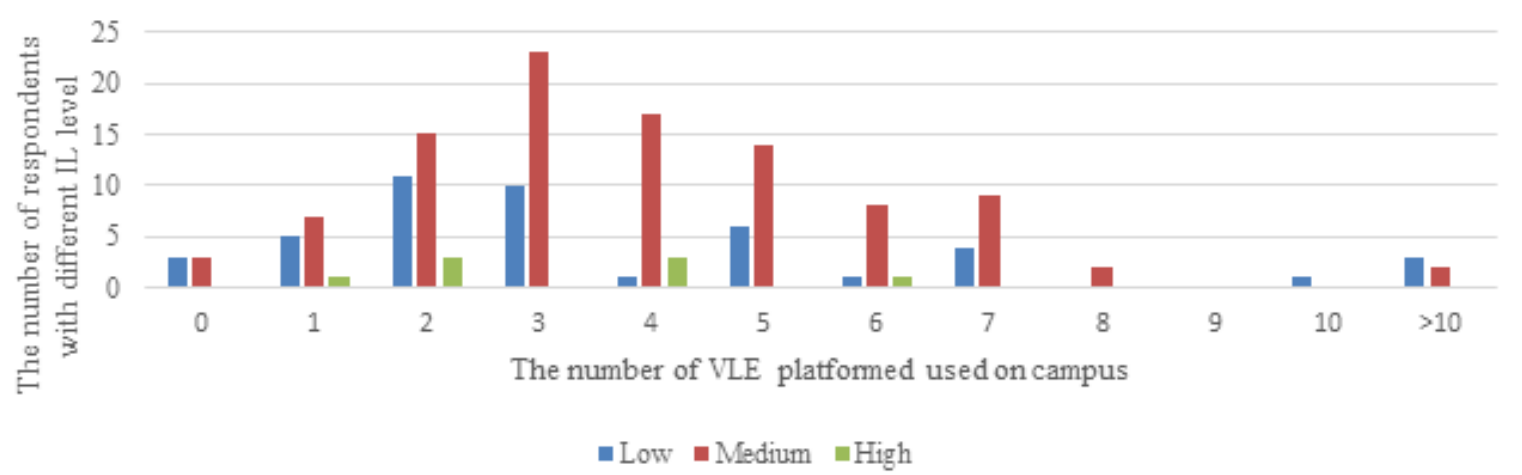

FIGURE 3. VLE platform number and number of respondents with different information literacy level

Figures 3, 4, 5 shows the relationship between VLE platforms number and sophomores' information literacy level in three traditional Chinese universities. The population distributions in Ningbo University (Figure 3) and Zhejiang University City College (Figure 6) are similar to the distribution of the total population covered in the study. In Ningbo University, 20 (64.52\%) sophomores rank in medium information literacy level, and 10 (32.26\%) sophomores rank in a low level; only one student, who can access 2 VLE platforms on campus reaches the high information literacy level. The peak of VLE platforms using among medium level sophomores are 2 and 3, and among low-level students is 2. In Zhejiang University City College, majority medium information literacy level sophomores have 3 VLE platforms accessible on campus, and this number is 1 among lowinformation-literacy-level sophomores. A special situation can be observed in Zhejiang University City College that, regardless the information literacy level, the number of VLE 
platforms sophomores can access is between 1 to 6 , but the majority students only believe they can access 2 or 3 VLE platforms.

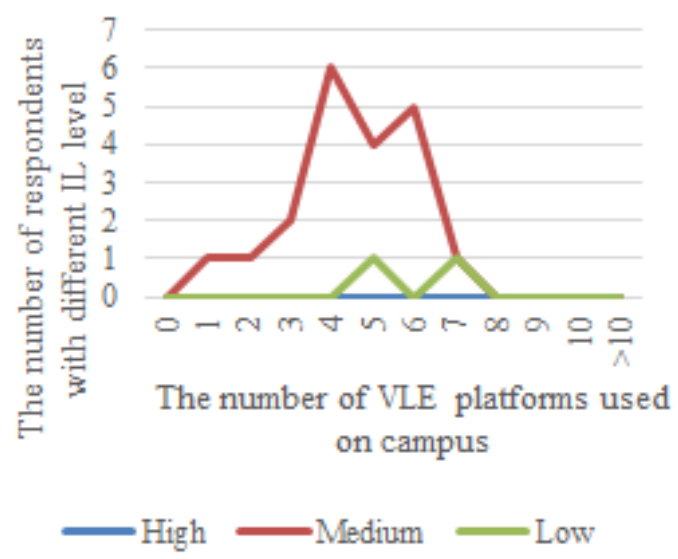

FIGURE 4. University of Nottingham Ningbo China

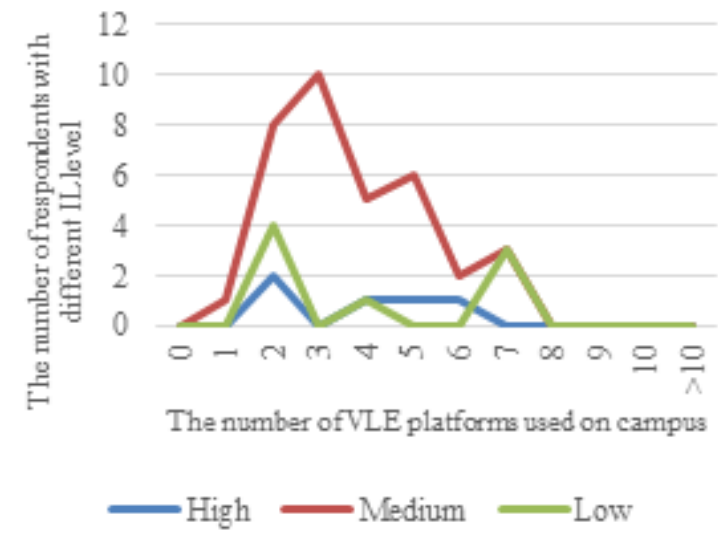

FIGURE 5. Wenzhou-Kean University

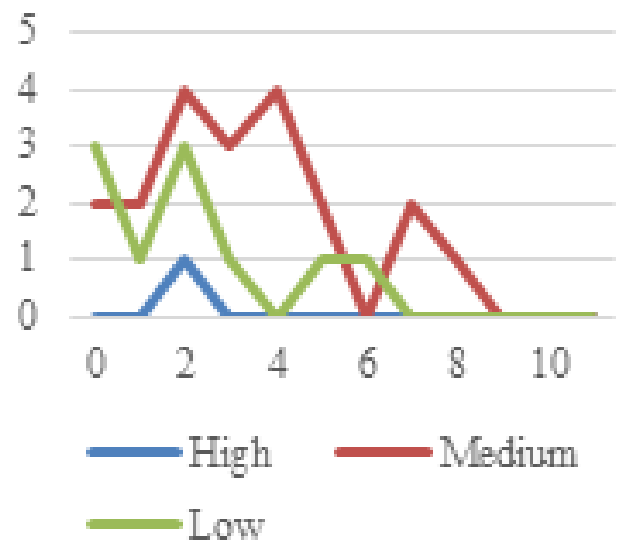

FIGURE 6. Ningbo University

In another traditional Chinese university, WMU (Figure 7), the distribution varies differently to some extent. Sopho- mores who can access to 3 VLE platforms on campus are the majority of both medium and low information literacy level. Two sophomores who rank in high information literacy level can both access to 4 different VLE platforms. However, this distribution is not very standing out; the sophomores' using amount of VLE platforms is near to equidistributional, which indicates that the individual information literacy level of WMU sophomores are close to the average level.

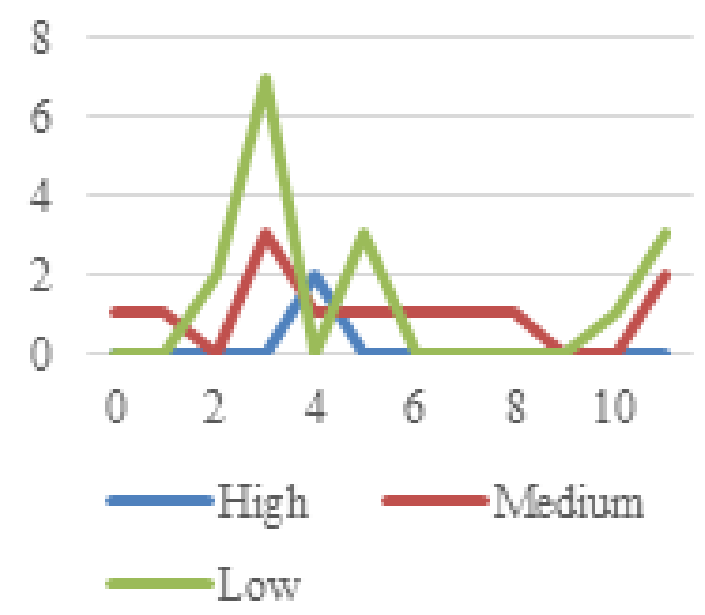

FIGURE 7. Wenzhou Medical University

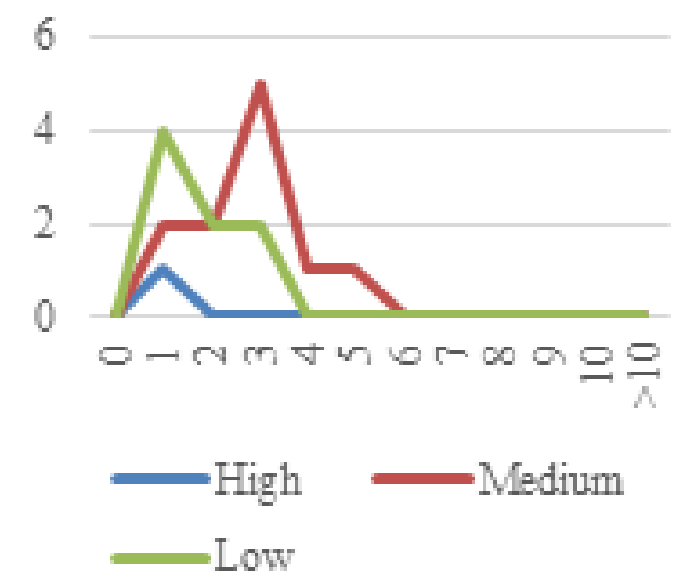

FIGURE 8. Zhejiang University city college

The average information literacy score for each university is in Table 1. Two Sino-western universities have higher average information literacy level, and the gap between Sinowestern universities and traditional Chinese universities involved in this research is relatively large. Compared to the data collected for VLE platforms' number, the researchers tend to draw a conclusion that, the number of VLE plat- 
forms which majority students are familiar with indicates the university's real situation of using VLE; combined with the distribution of sophomores' population accessing different VLE platforms' number, Sino-western university stu- dents, averagely, have higher information literacy level with more VLE platforms access opportunity than students in traditional Chinese university.

TABLE 1. The average information literacy score

\begin{tabular}{|c|c|c|c|c|}
\hline $\begin{array}{l}\text { University of Not- } \\
\text { tingham Ningbo }\end{array}$ & $\begin{array}{l}\text { Wenzhou Medical } \\
\text { University }\end{array}$ & Ningbo University & $\begin{array}{l}\text { Wenzhou Medical } \\
\text { University }\end{array}$ & $\begin{array}{l}\text { Zhejiang Univer- } \\
\text { sity City College }\end{array}$ \\
\hline 173.1364 & 167.0625 & 149.5484 & 137.2333 & 146.85 \\
\hline
\end{tabular}

As Figure 8 shows, the average information literacy score and the average number of used VLE platforms of each school are likely to have a positive correlation except for Wenzhou Medical University. Since the effects of the number of VLE platforms on information literacy are not strong, there might be some other factors which influence students' information literacy. Ten sophomores who completed the rating scale were interviewed. One of the interviewees has high, seven have medium and two have low information literacy level. There was some consistency among the interviewees with same level of information literacy.

From the perspective of source selection, when assigned academic papers which require students to use sources, the two interviewees with low-level information literacy tend to use sources from the platforms which can be edited by everyone but easy to get. The typical platforms they use frequently are Zhihu and Baidu-Baike, and they stated that they have never heard about any database. Both of the interviewees consider they are credible websites to get information. In addition, the interviewees hardly consider the publish date of the sources when citing them. The interviewees with medium information literacy level command the basic knowledge of searching, evaluating and applying sources. They tend to use authoritative platforms as their searching channels. For example, one interviewee from the
University of Nottingham Ningbo China usually uses Nusearch (a search tool contained in Moodle) and Google Scholar to search information; while another one from WenzhouKean University often uses ProQuest Central. The type of sources the interviewees preferred are journal articles. They pay close attention to details of the sources like the publish date, citation numbers and credibility. The interviewee who has high information level had the same ideas as students with medium information literacy. Besides, she regarded good sources as objective, credible statistic involved and related to the topic the searcher needs. Other non-academic sources like forums are used as assistance to help her acquire new directions or inspirations. According to interviewees, different universities vary in VLE teaching. Wenzhou-Kean University offers workshops to teach how to use school online library and provides a related video in students' freshmen year. Many professors teach students how to search needed information in their courses. Zhejiang University City College interviewees are only provided with real library coaching at the very beginning of their first semester. Therefore, they considered themselves weak in searching information on the Internet. There might be a relationship between the VLE teaching and students' information literacy.

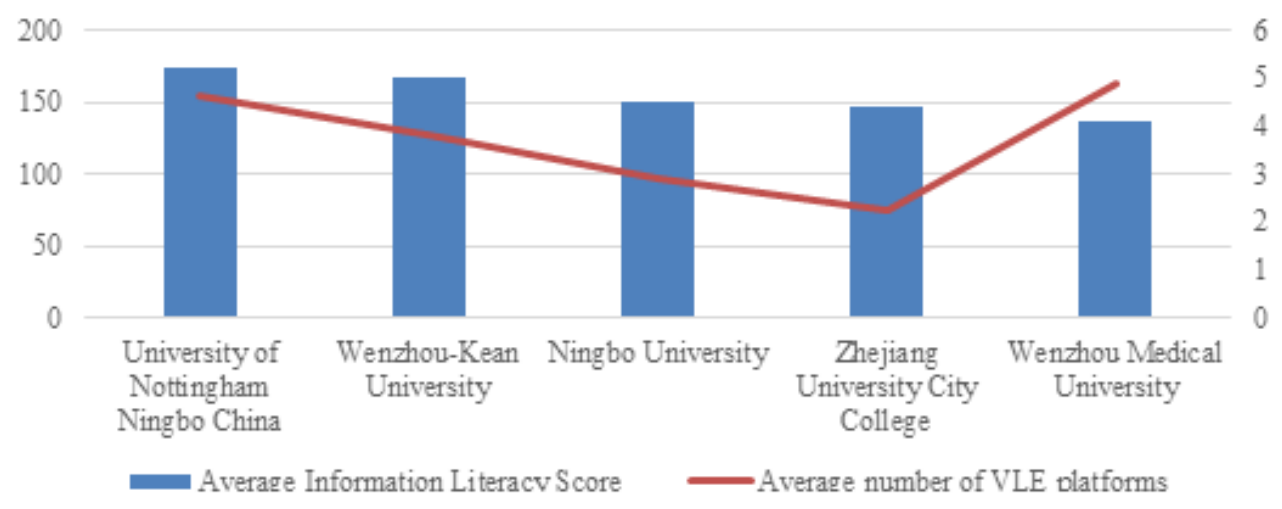

FIGURE 9. The average number of VLE platforms 
As Figure 9 reflects, the average number of VLE platforms Wenzhou Medical University respondents access is the highest among five universities. The two interviewees from Wenzhou Medical University, both noted that they only use VLE platforms to take quizzes and hand in homework, so did interviewees from Zhejiang University City College. The interviewees from University of Nottingham Ningbo China use Moodle, a VLE platform, which allows interactions between students and teachers, resource sharing, information searching, plagiarism examining and so on. There might be a relationship between the function variety of VLE platforms students access to and their information literacy level.

\section{DISCUSSION}

This study has found that the number of VLE platforms adopted in university has very little but non-negligible effects on students' information literacy level; in other word, the relationship between VLE platforms and students' information literacy level has an unclear relationship, which cannot be specifically concluded and needs further research. Also, the complexity and the instructions on VLE platforms usage appear to be related elements that should be covered in the future research.

According to the rating scale designed for testing individual information literacy, sophomores from three traditional Chinese Universities: Ningbo University, Wenzhou Medical University, and Zhejiang University City College, have lower information literacy averagely; sophomores studying in two Sino-western universities: Wenzhou-Kean University and the University of Nottingham Ningbo China have higher information literacy averagely. The number of VLE platforms adopted in each university mainly distributes from 0 to 10 , but the majority participants can access to 3 to 6 different VLE platforms on campus. The situation in traditional Chinese universities share the feature of the general distribution established between students' information literacy level and the number of VLE platforms; that the peak among low information literacy level students usually appears in 2 VLE platforms, and this number changes to 3 when it comes to medium information literacy level students. In Sino-western universities, the majority participants rank in medium information level, and a large number of VLE platforms they can access are distributed on 3.
Implications for freshmen and sophomores in the five universities (and all undergraduate university students in China)

The freshmen and sophomores from studied universities need to enhance their information literacy to be more competitive. Students from three traditional universities can learn some specific data analysis skills to improve research effectiveness (Judy, 2016). Some details should be thought through, like the author's name, publish date, source credibility, source type, citation frequency, number of papers cited by core periodicals, citation time distribution and difference, journal distribution, etc. Students from Sinowestern universities can explore the functions of different VLE platforms and get familiar with the VLE platforms they can access.

\section{Implications for high education institutions}

High education institutions should try to set some course or tutorial to help students, especially freshmen, to be more familiar with the VLE platforms they can access on campus. Instructors can significantly improve students' information literacy through appropriate intervention (Britt \& Aglinskas, 2002).

\section{CONCLUSION}

To some extent, researchers of this study can conclude that the number of VLE platforms adopted on campus can affect students' information literacy; however, the relationship does not accord with the hypothesis created previously, more accessible VLE platforms on campus might not enhance students' information literacy.

However, after comparing the distribution of the majority participants' accessed VLE platforms' amount, researchers of this study found that the number of VLE platforms students are familiar with might have more relevant relationships between students' information literacy. The familiarity, using frequently, the acceptance of a certain VLE platforms, VLE platform's complexity and other elements might affect students' information literacy in a VLE required environment.

Based on interviews, the source selection tendencies of students with different information literacy levels are different. The students with higher information literacy level are more likely to search information on credible channels and evaluate the source quality accurately. The school coaching of VLE platforms using and the function variety of VLE platforms may have an impact on students' information literacy. 


\section{LIMITATIONS AND RECOMMENDATIONS}

The research should cover a larger population to arrive at more practical conclusions. Since the research was trying to find the relationship between the number of VLE platforms and Chinese university students information literacy, the population should be enlarged to cover as many provinces as possible. In the further study, an ideal sample size should successfully represent the total population, and considers gender, students' age, students" major, the academic and real environment surrounding students and other elements; also, all the elements shall be considered as possible variable that can illustrate the relationship between VLE and students' information literacy.

Researchers of further study should also consider participants' attitude toward the research as an essential point. The research should be conducted in an environment where all participants are aware of the significance of this re- search, and have the willingness to participate carefully. More technology tools can be used to support the research to be conducted more successfully.

\section{ACKNOWLEDGEMENT}

The researchers of this paper would like to express great thankfulness to Dr. Richard J. Braxton for his encouragement and expert advice throughout this difficult and longlasting project. We would also like to thank peers in five universities selected in this research for their cooperation and patience of participating in the surveys. We would also like to show our gratitude to the interviewees for their devoted attitude and the time for helping us. We are also grateful to anonymous peers in Wenzhou-Kean University for their comments on an earlier version of this paper; although any errors are our own and should not tarnish the reputations of these esteemed persons.

\section{REFERENCES}

Boonyarattanasoontorn, P. (2017). An investigation of Thai students' English language writing difficulties and their use of writing strategies. Journal of Advanced Research in Social Sciences and Humanities, 2(2), 111-118. doi:https://doi.org/ 10.26500/jarssh-02-2017-0205

Britt, M. A., \& Aglinskas, C. (2002). Improving students' ability to identify and use source information. Cognition and Instruction, 20(4), 485-522. doi:https://doi.org/10.1207/s1532690xci2004_2

Hansson, S. O. (2005). Decision theory a brief introduction (Unpublished master's thesis). Department of Philosophy and the History of Technology, Royal Institute of Technology (KTH) Stockholm, Sweden.

Hashim, H., Salam, S., \& Mahfuzah Mohamad, S. N. (2017). Investigating learning styles for adaptive Massaive Open Online Cource (MOOC) learning. Journal of Advances in Humanities and Social Sciences, 3(5), 282-292. doi:https://doi.org/ 10.20474 /jahss-3.5.4

Irvine, J. (2015). Enacting Glasser's (1998) choice theory in a grade 3 classroom: A case study. Journal of Case Studies in Education, 7(5), 1-30.

Judy, W. (2016). Critical analysis and information literacy. Retrieved from https://goo.gl/deFiFi (accessed on 21 June 2017)

Klomsri, T., \& Tedre, M. (2016). Poor information literacy skills and practices as barriers to academic performance: A mixed methods study of the university of Dar es Salaam. Reference \& User Services Quarterly, 55(4), 293-305. doi:https:// doi.org/10.5860/rusq.55n4.293

Koroieva, M. I. . K. I., I. (2017). Small rural schools on the edge of survival: Comparative assessment of stakeholders' perspectives in Latvia and Norway. Journal of Advances in Humanities and Social Sciences, 3(4), 214-225. doi:https:// doi.org/10.20474/jahss-3.4.3

Martins, L. L., \& Kellermanns, F. W. (2004). A model of business school students' acceptance of a web-based course management system. Academy of Management Learning \& Education, 3(1), 7-26. doi:https://doi.org/10.5465/ amle.2004.12436815

McClelland, D. (1961). The achievement society. East Norwalk, CT: Appleton Century Crofts.

Ngwaru, J. M. (2017). Multi-literacies pedagogy design: The case of focused ethnographic research and catalytic validity in literacy development. International Journal of Humanities, Arts and Social Sciences, 3(2), 31-43. doi:https://doi.org/ 10.20469/ijhss.3.20001-2

Oxford University Press. (2016). Learn about virtual learning environment/course management system content. Retrieved from https://goo.gl/QzYpKE (accessed on 15 June 2017)

Parmigiani, G., \& Inoue, L. Y. (2009). Decision theory principals and approaches. Chichester, UK: John Wiley \& Sons, Ltd. 
Pengmanee, S. (2016). Developing students' mathematical reasoning ability based on constructivist approach. Journal of Advances in Humanities and Social Sciences, 2(4), 221-231. doi:https://doi.org/10.20474/jahss-2.4.3

Rabahi, M., Yusof, H., \& Awang, M. (2016). Model of hope: Leading learning among the indigenous Orang asli students. International Journal of Humanities, Arts and Social Sciences, 2(1), 1-12. doi:https://doi.org/10.6007/ijarbss/v6-i12/ 2480

Silva, H. M. S. V., \& Madushani, R. A. I. (2017). The impact of human resource competencies of front line employees on tourist arrivals of unclassified hotels in Western province, Sri Lanka. Journal of Advanced Research in Social Sciences and Humanities, 2(1), 09-16. doi:https://doi.org/10.26500/jarssh-02-2017-0102

Siti Fatimah, A. Z., Norhafizah, M. S., Noryanti, M., Rozieana, K., \& Hassan, R. G. (2015). A study of students' performance in calculus and their attitudes toward the course using tripartite model. International Journal of Humanities, Arts and Social Sciences, 1(1), 30-35. doi:https://doi.org/10.20469/ijhss.20005

Suharti, L., \& Pramono, A. (2016). Cultural intelligence among indonesian students: Role of international experiences and their impact on the development of social network and adaptive performance. Journal of Advances in Humanities and Social Sciences, 2(3), 182-194. doi:https://doi.org/10.20474/jahss-2.3.6

Supratman, L. P. (2015). A case study of classroom seating arrangement to promote students' communication and interactivity in Telkom university. International Journal of Humanities, Arts and Social Sciences, 1(3), 130-133. doi:https:// doi.org/10.20469/ijhss.20005-3

Webber, S., \& Johnston, B. (2000). Conceptions of information literacy: New perspectives and implications. Journal of Information Science, 26(6), 381-397. doi:https://doi.org/10.1177/016555150002600602

Weiler, A. (2005). Information-seeking behavior in generation y students: Motivation, critical thinking, and learning theory. The Journal of Academic Librarianship, 31(1), 46-53. doi:https://doi.org/10.1016/j.acalib.2004.09.009

Yin, R. (1984). Case study research: Design and methods, beverly hills. California, CA: Sage Publications.

Zeeman, R. D. (2006). Glasser's choice theory and purkey's invitational education allied approaches to counseling and schooling. Journal of Invitational Theory and Practice, 12, 46-51. 


\section{APPENDIXES}

\section{Interview Questions}

1. What kind of VLE platforms do you use on campus? Please tell us their names and functions, and in which course(s) you use them. 2. How often do you use these VLE platforms in one course? Why?

3. Do you know how many VLE platforms you can access in your university totally?

4. Can you tell the difference of VLE platforms and usages amongst different courses or majors?

5. In which course will you use VLE platforms to gather information?

6. How do you think the information you gathered from VLE platforms? Why?

(How do you determine the information you gathered from VLE platforms is high quality?) e.g. will you care about the publish date, the website credibility; do you only use search engines like Baidu or you use other tools.)

7. Can you briefly list the information type you gathered from VLE platforms?

\section{Survey}

DIRECTIONS: This instrument is composed of 40 statements concerning feelings about finding and disseminating research information. By answering the questions listed below, we will evaluate your information literacy level; try to identify the relationship between information literacy level and VLE using situation.

*only sophomores are welcome to participate.

1. Your university? (Please Choose)

- Wenzhou-Kean University

- The University of Nottingham Ningbo

- Ningbo University

- Wenzhou Medical University

- Zhejiang University City College

2. Your age? (Please choose)

- 16

- 17

- 18

- 19

- 20

- 21

- 22

- Above 22

3. Your gender?

- Male

- Female

4.Your major?

5. The number of VLE platforms you use on campus? (E-learning systems, or VLEs, is a web-based communications platform, which offers students the opportunity to access different learning tools or learning resources without time or place limitation. It is designed to make all the component of a class, such as course information, course content, teacher assistance, discussion boards, document sharing systems, and academic material be more available to students (Martins \& Kellermanns, 2004). It has the potential to enhance the influence of face-to-face teaching (in class), and it might bring effectiveness of communication, which is among students and teachers.)

6. The rating scale "Information Competency Assessment Instrument" retrieved from http://goo.gl/mSXJsb $1 \& 4 \& 7$

Strongly agree \& neither agree \& disagree—strongly agree 